\title{
Quantifying uncertainties in the measurement of tephra fall thickness
}

\author{
SL Engwell*, RSJ Sparks and WP Aspinall
}

\begin{abstract}
The uncertainties associated with tephra thickness measurements are calculated and implications for volume estimates are presented. Statistical methods are used to analyse the large dataset of Walker and Croasdale J Geol Soc 127:17-55, 1971 of the Fogo A plinian deposit, São Miguel, Azores. Dirichlet tessellation demonstrates that Walker and Croasdale's measurements are highly clustered spatially and the area represented by a single measurement ranges between 0.5 and $10 \mathrm{~km}^{2}$. K-means cluster analysis shows that lower thickness uncertainties are associated with closely spaced measurements. Re-examination and analysis of Fogo A fall deposits show thickness uncertainties are about 9\% for measured thickness while uncertainty associated with natural variance ranges, between 10 and $40 \%$, with an average error of 30\%. Correlations between measurement uncertainties and natural variance are complex and depend on a unit's thickness, position within a succession and distance from source. Normative error increases as tephra thickness decreases. The degree to which thickness measurement error impacts on volume uncertainty depends on the number of measurements within a given dataset and their associated uncertainty. The uncertainty in volume associated with thickness uncertainty calculated herein for Fogo A is $1.3 \%$, equivalent to a volume of $0.02 \mathrm{~km}^{3}$. However uncertainties associated with smaller datasets can be much larger; for example typically exceeding $10 \%$ for less than 20 data points.
\end{abstract}

Keywords: Tephra thickness; Observational uncertainty; Natural variance

\section{Background}

In volcanology, pre-historic eruption magnitude estimates rely on measured tephra thickness data, often presented as an isopach contour map (Thorarinsson and Sigvaldon 1972; Pyle 1989, 1995; Fierstein and Nathenson 1992; Bonadonna and Houghton 2005; Sulpizio 2005; Bonadonna and Costa 2012). Assessment of tephra volume without the need for drawing isopach maps is a new development (Burden et al. 2013). These approaches are typical of a class of multiscale modelling problems in physical sciences, where traditionally, a macroscopic model, based on simplifying symmetry or linearization considerations, is used to characterize to the first order a particular physical phenomenon. Many natural processes involve influential smaller scale effects, neglect of which can sometimes cause such macroscopic models to fail to capture important details adequately. For instance, in meteorology, complex interactions between weather systems at different

\footnotetext{
* Correspondence: sam.engwell@bristol.ac.uk

School of Earth Sciences, University of Bristol, Wills Memorial Building,
} Queen's Road, Bristol BS8 1RJ, UK spatial and time scales are expressed in sophisticated multiscale models. However, such models become intractable in the limit by grid size and time-step constraints, and by limitations in numerical modeling of uncertainties. Little work has been conducted on quantifying, even at first order, the uncertainties associated with the tephra thickness measurements on which volume estimates are based, let alone give consideration to confounding or competing multiscale effects at increasing levels of granularity or gridding. Here we aim to determine how well thickness measurements characterize deposit thickness in the context of tephra volume assessment.

The topology of a tephra fall deposit depends principally on the duration and dynamics of the eruption plume, its interaction with wind, the original total grain size distribution of the ejecta (e.g. Walker 1973; Sparks et al. 1997; Bonadonna and Houghton 2005; Rust and Cashman 2011) and aggregation processes (e.g. Brazier et al. 1983; Brown et al. 2011). Tephra thickness is also affected by factors unrelated to eruption dynamics, for example: variation in topography, re-mobilisation, bioturbation,

\section{实}


compaction and soil formation. The common lack of consolidation of volcaniclastic deposits means that, postdeposition, deposits are often thinned or removed by grainsize-dependent erosional processes, with anomalously thick deposits forming in topographic lows. In addition, compaction, especially of fine-grained $(<2 \mathrm{~mm})$ ash deposits leads to increased deposit density and a thickness decrease of up to $50 \%$ over timescales of less than two years (Guichard et al. 1993; Blong and Enright. 2011). For this reason, Bonadonna and Houghton (2005) advocate measurements of mass per unit area as opposed to thickness, removing the need to correct for compaction or density variations. This said, erosion effects can remain an issue if immediate measurements are not made and it is only usually practical to determine mass per unit area in newly erupted material recovered from collecting trays, whereas mass measurements are usually impractical with most pre-historic deposits exposed in outcrops. As a result, thickness is likely to remain the measure of choice in palaeovolcanological studies.

The controlling assumption when analyzing and modelling tephra deposits is that tephra thickness is uniform over local areas, with deposits mantling topography and occurring everywhere except on very steep slopes (Duffield et al. 1979; Wright et al. 1980; Cas and Wright 1995). Tephra volume estimates derived from isopach maps rely on thickness trends being controlled by eruptive and atmospheric rather than depositional processes. Tephra fall models (e.g. TEPHRA2, FALL3D, HAZMAP) also adopt this assumption for computational reasons. The physics behind modeled tephra thickness is limited to processes in the simulated plume and, therefore, tephra is represented as depositing on a 'flat' surface. While digital elevation models are required to process the spatial distribution of modeled deposits and for presenting results, actual topography has no effect on calculated deposit thickness in such models. Inverse tephra modelling techniques determine optimised parameters by using a mathematical algorithm to assist in determination of a best-fit parameter set (Connor and Connor 2006). The optimality of input parameters is determined by calculating goodness of fit of model to measurements, with the best set of parameters resulting in a goodnessof-fit value of zero. However, this value is never reached for a number of reasons, one of which being that random variation in tephra deposits are not accounted for in the model (Connor and Connor 2006). Providing estimates of uncertainty for thickness measurements would enable better understanding of controls on model fit to data and therefore of uncertainties in model results.

Uncertainties in tephra thickness can be separated into two main types. The first are those associated with natural variation related to the physical process of deposition, remobilization and preservation. Secondly, measurement accuracy (here termed 'observational uncertainty') may be affected by differing measurement techniques. These uncertainties affect how well a single measurement represents deposit thickness in the area surrounding the measurement location. To-date, the effect of these factors on measurement uncertainty has not been quantified. In this study, we explore local variations in the Fogo A deposit (Figure 1), Agua de Pau volcano on the Island of São Miguel, Azores. The dataset of Walker and Croasdale (1971) provides one of the most complete datasets of subaerial tephra thickness anywhere in the world, and enables analysis of the effects of measurement spatial distribution on interpreting deposits. We provide additional insights into the variability of tephra thickness of units that comprise the Fogo A deposit using supplementary data obtained by five scientists during a fieldwork campaign in 2011.

\section{The Fogo A Deposit}

The Fogo member A deposit was produced during a trachytic Plinian eruption approximately 5000 years ago (Moore 1990). Walker and Croasdale (1971) and Bursik et al. (1992) separated the deposit into two volumetrically dominant fallout deposits, a lower syenite-poor Plinian fall and an overlying, syenite-rich Plinian fall deposit, separated by pyroclastic density current (PDC) deposits. Bursik et al. (1992) inferred the lower syenite-poor Plinian deposit formed while there was a southerly wind. The coarser grained syenite-rich deposit has a nearaxisymmetric distribution and was formed during a more intense eruptive phase during which the plume reached an estimated height of $21 \mathrm{~km}$ (Bursik et al. 1992).

The thickness measurements from Walker and Croasdale (1971) relate to whole deposit thickness incorporating both syenite-poor and syenite-rich pumice fall deposits and interlayered PDC deposits. The measured PDC deposits are thin (typically less than $20-30 \mathrm{~cm}$ ) and occur only in proximal $(<10 \mathrm{~km})$ localities. The Fogo A deposit has a maximum total thickness exceeding $20 \mathrm{~m}$ on the rim of the caldera decreasing to $5 \mathrm{~m}$ at the coast $6 \mathrm{~km}$ south west of the vent (Figure 1, Walker and Croasdale 1971). Erosion, weathering and soil formation prevent deposits of less than $0.25 \mathrm{~m}$ being easily recognized. Information to the north and south is limited because marine sediments that might contain the Fogo A tephra layer have not been sampled.

\section{Statistical Analysis}

The Fogo member A dataset of Walker and Croasdale (1971) contains 250 subaerial tephra thickness measurements distributed axi-symmetrically around the vent. A small number of proximal deposits contain thin fine-grained PDC deposits but these contribute a minor fraction of the total thickness and are not observed to 


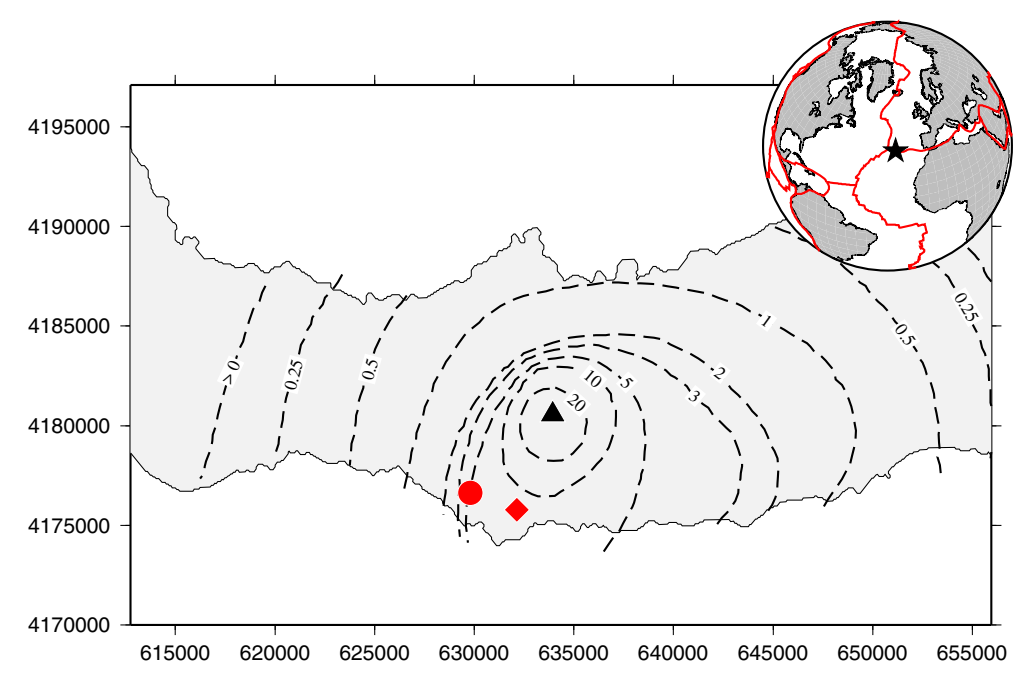

Figure 1 Map of part of São Miguel Island, Azores (geographic location shown in inset by black star), with the original isopachs of Walker and Croasdale (1971). The eruptive source of the Fogo A deposit is shown by the black triangle. Two localities were studied in detail. At Loc 2 (red circle; 629817 E 4176612 N) the Fogo A deposit was measured at a number of outcrops within an area of $\sim 200 \mathrm{~m}^{2}$. At Loc 5 (red diamond; $632141 \mathrm{E} 4175785 \mathrm{~N}$ ), measurements of the deposit were taken over a scale of $\mathrm{cm}$ to tens of metres.

have been erosive. This enables assessment of deposit heterogeneity and large-scale spatial variance. The corresponding area that a single measurement can represent is dependent on the natural variability of accumulation, thickness decay with distance, measurement spacing, outcrop identification and accessibility. To-date no studies have focused on the effect of natural variability on thickness interpretation and observational uncertainty, and therefore there is little empirical guidance on what is the appropriate resolution for measurements.

The area ascribed to each Fogo A thickness measurement is delineated using Dirichlet tessellation (applied using the CRAN R Statistics package 'Deldir'). The planar area of interest is divided into territories according to the location of each measurement and spacings between adjacent measurements (Figure 2A). A 'territory' is assigned to each measurement consisting of the area that is closer to a given measurement than any other (Diggle 1983), and delineates an area that contains one, single point measurement. On the assumption that such areas are small, Dirichlet tessellation is used to define territories where each measurement is representative of the territory. Where a territory area is large, the single sample may not represent accurately thickness across the whole territory, leading to the need for additional statistical modelling to compensate for any wide scale thinning trends that may exist.

In the case of Fogo A, the tesselation results display a clustered distribution in medial distances, particularly along the coast (Figure 2A). With distance from source, measurement spatial distribution becomes more uniform. Most measurements represent an area of between
0.5 and $10 \mathrm{~km}^{2}$, but there is a large amount of scatter (Figure 2B). These findings are attributed to significant spatial variations in the density of good outcrops and difficulties in locating suitable places on São Miguel (e.g. via road access to outcrops) at which to measure thickness at greater distances from source.

The clustered nature of measurements enables analysis of the relationship between neighboring measurements. Such measurements may be correlated because of scale-related effects in natural depositional processes (due to deposition in similar environments or involving similar tephra characteristics e.g. grain size), and hence are not truly independent random samples of an underlying distribution. A K-means clustering algorithm was applied (CRAN R Statistics package 'kmeans') to assess, numerically, associations between close neighbour points, following the method of Hartigan and Wong (1979). K-means clustering analysis is used to segregate measurement locations in $\mathrm{N}$ dimensions (here, $\mathrm{N}$ is two-dimensional, referring to the latitude and longitude of the data point locations) into $\mathrm{K}$ separate clusters such that the withincluster deviation sum of squares across all $\mathrm{N}$ dimensions is minimized (Hartigan and Wong 1979). Although in this case $\mathrm{N}=2$ relates just to the location of data points, additional parameters could be invoked to more fully characterize measurements for a marked point process, e.g. particle size. In the present analysis, the emphasis is on the spatial distribution of measurements and therefore a point-to-point distance calculation is used to assemble objective clusters; within-cluster sum of squares of paired distances is the calculated measure for determining cluster membership. A 'local' minimum is obtained if 


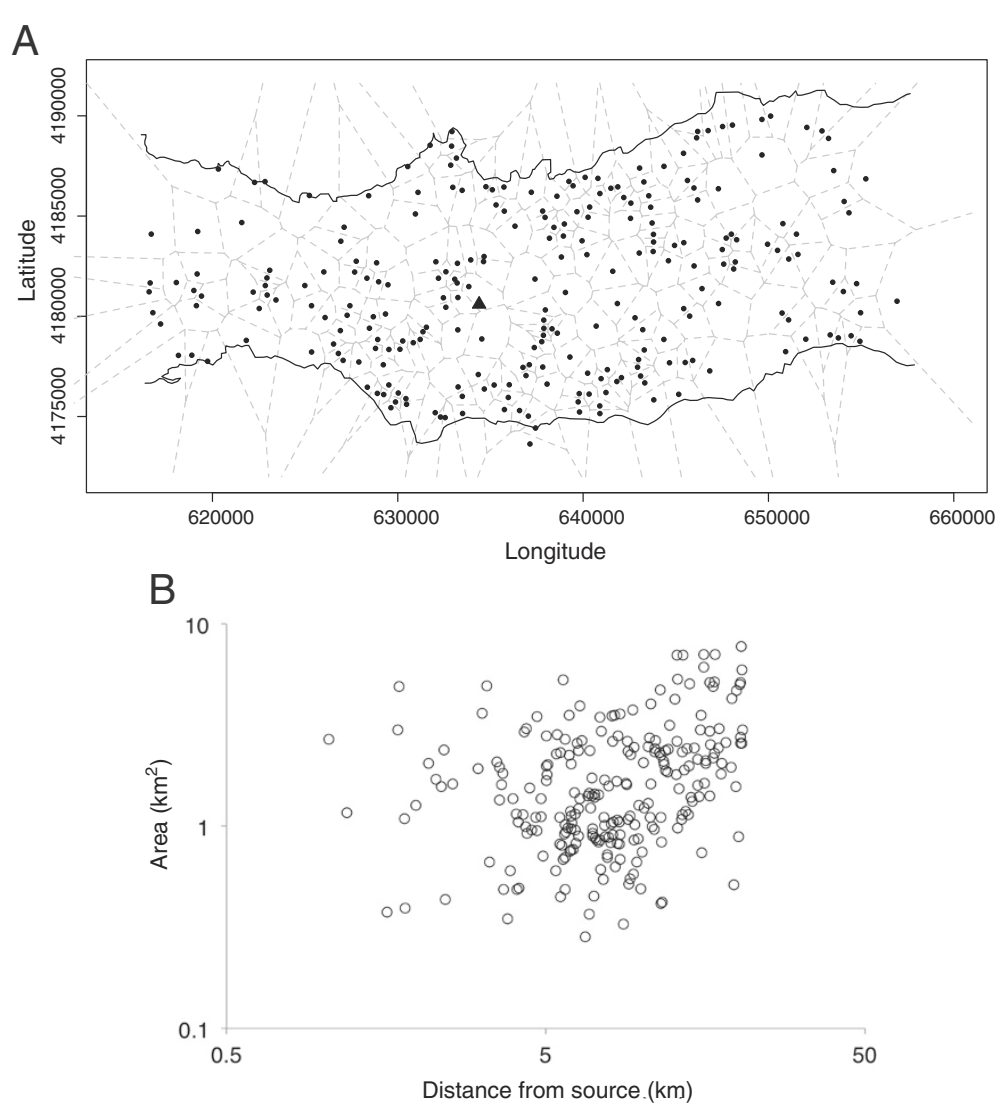

Figure 2 Dirichlet tessellation results for the Fogo A deposit. A. The territory that each thickness measurement represents. For the outer measurements, only the subaerial area is considered. There is a clear clustering of measurements particularly at medial distances. B. Area encompassed by individual cells versus distance from source. The data shows a large amount of area size scatter at all distances from source, reflecting big spatial sampling density variations.

moving a particular measurement point from one cluster to another does not reduce the overall within-cluster sum of squares. In other words, cluster memberships are objectively defined for the selected number of clusters $\mathrm{K}$, across the associated $\mathrm{N}$-dimensional parameter space. Following this method, the Fogo A thickness measurements of Walker and Croasdale (1971) were split into five, ten (Figure 3A) and twenty clusters to examine their clustering properties.

For each cluster, thickness variation was calculated using the standard deviation of all enclosed measurements and is expressed as a percentage relative to cluster average thickness (Figure 3B). Within a single cluster, measurements should have related thickness and therefore low standard deviation. When the dataset is split into a greater number of clusters the percentage error decreases. With increasing cluster number, the spatial area delineated by each cluster decreases and hence the encompassed measurements are more similar in terms of their immediate depositional environment and consequently thickness estimates. The within-cluster percentage error (calculated as one standard deviation from cluster mean thickness) decreases with distance from source when 5 and 10 clusters are used showing that over similar scales, proximal deposits are more variable than distal deposits. When the data are split into twenty clusters, the errors do not decrease with distance from source but remain constant. This latter error trend is considered to directly reflect local variation. The relationship between the number of clusters and within cluster error (Figure 3C) indicates that this trend can be represented by a power-law function with lower errors when more clusters are used.

\section{Thickness with distance from source: exponential versus power law}

Tephra thickness decay trends are sometimes described by an exponential function with distance from the vent (Thorarinsson 1954) or, more usually, by the square root of isopach areas (e.g. Pyle 1989). However, with distance from vent some deposit thicknesses fit better to either a Power-law (Bonadonna and Houghton 2005) or a Weibull distribution (Bonadonna and Costa 2012). The natural $\log$ of the Fogo A data display a coherent trend 


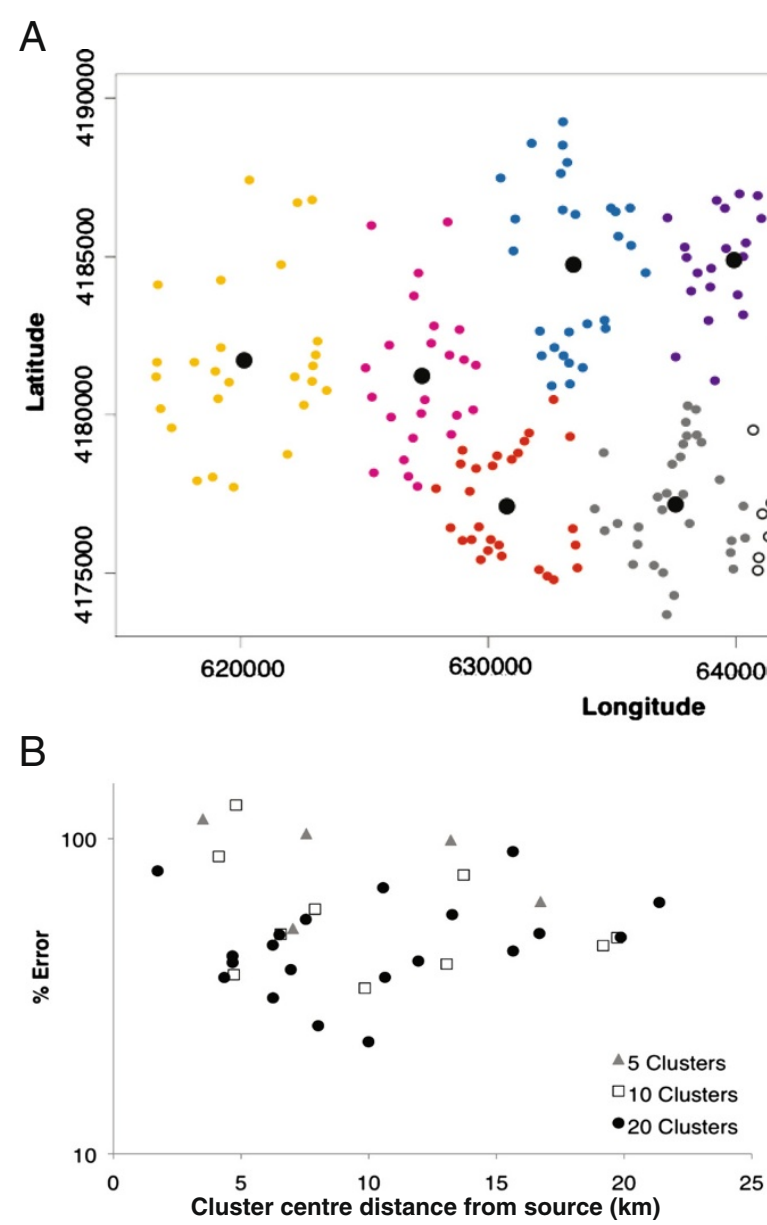

Figure 3 The Fogo A data were analysed using a K-means cluster identification algorithm (see text) to interrogate spatial distribution patterns. A. The data is split into 10 clusters based on the spatial distribution of thickness measurements. Solid black circles represent the centre of each cluster with the coloured markers showing the data points that belong to each cluster. B. Percentage error determined as one standard deviation departure from mean of each cluster with distance. Here the effect of increasing the number of clusters in the analysis becomes more evident with percentage error greater with fewer clusters. C. The average percentage errors for different numbers of K-means cluster divisions decrease following a power-law trend.

with distance from source (Figure 4A) with some scatter but well defined upper and lower bounds. At distances greater than $5 \mathrm{~km}$ the data bifurcate. Regression analysis provides $R^{2}$ values that are similar for both exponential and power-law trends (Table 1). However, the exponential trend is a significantly better fit because data points scatter more symmetrically across the thickness range. In contrast, measurements at distances greater than $10 \mathrm{~km}$ from source mostly lie below the power law regression line, while measurements closer than $10 \mathrm{~km}$ mostly plot above the line.

To investigate the bifurcation in thickness decay trends at distances greater than five $\mathrm{km}$ and subsequent effect on function fit, the data were split into four quadrants using north-south and east-west dividing lines (Figure 4B) that intersect at the source. This choice reflects the inferred wind-influenced asymmetries of the deposit.
The bifurcation is explained by azimuth-dependent differences in rate of thickness decrease around the vent. Thickness decreases more quickly to the west associated with changes in wind strength and direction in the latter stages of the eruption (Walker and Croasdale 1971; Bursik et al. 1992). $R^{2}$ values are much greater for each individual quadrant compared with a single regression although some scatter is still noted (Table 1), but are similar for both power-law (Figure 4C) and exponential (Figure 4D) regression. Power-law regression fits significantly better when the dataset is split into quadrants compared to when the dataset is considered as a whole. In summary, the whole dataset is better represented by an exponential function than a power law, but splitting the data into quadrants allows much better estimation of thickness trends with distance from source with little difference in fit between exponential and power-law trends. 


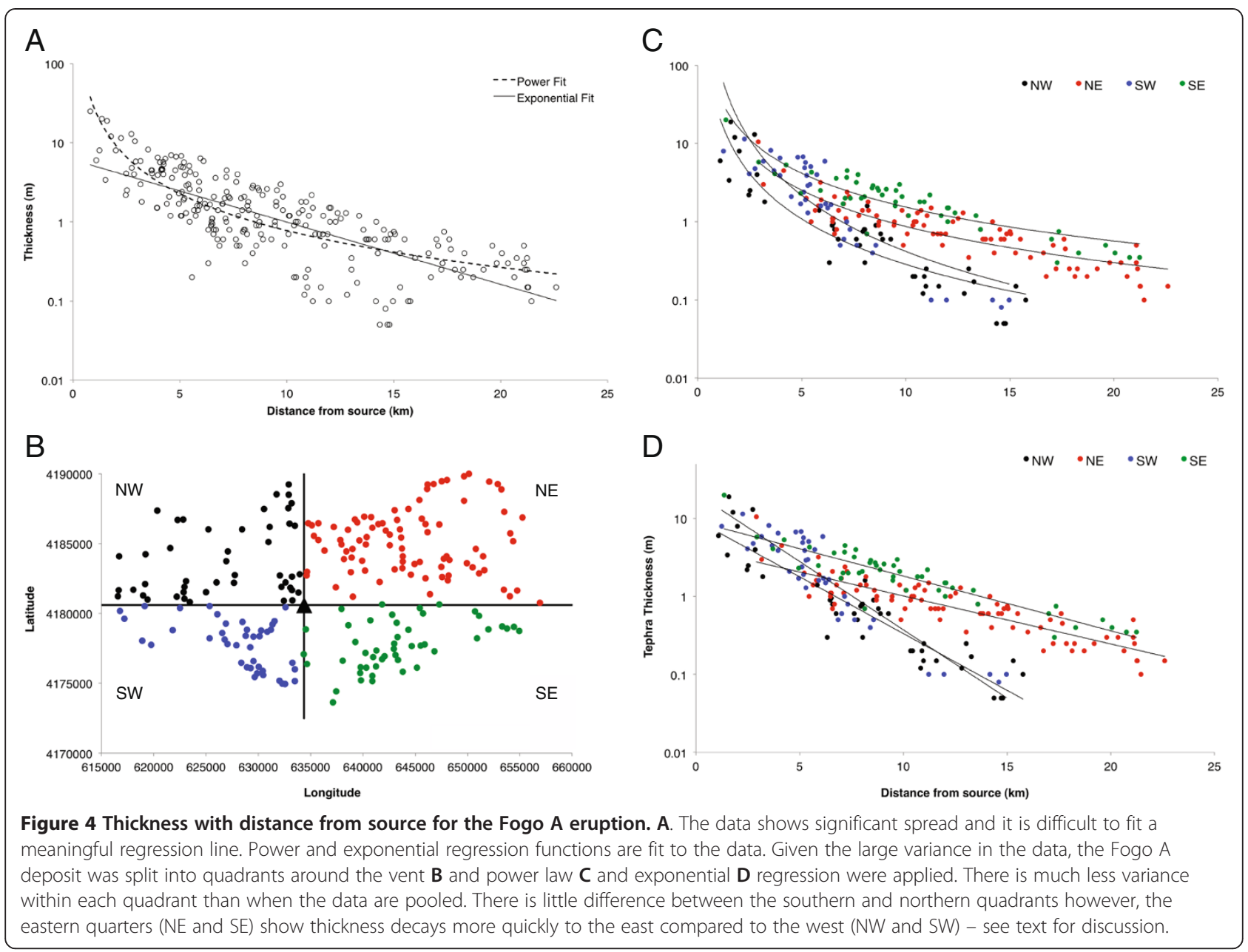

\section{Field Measurements}

To extend the present analysis and investigate the scatter in thickness data, new thickness measurements of the Fogo A deposit were gathered. The key factors that contribute to observational uncertainty in terms of thickness estimation are determined and their effects quantified. Here, definition of the Fogo A deposit follows Bursik et al. (1992), where the deposit is divided into a syenite-poor Plinian fall deposit, pyroclastic density current deposits and syenite-rich Plinian fall deposit as

Table 1 Regression best fit equations for the Walker and Croasdale (1971) Fogo A thickness data as a function of distance from source

\begin{tabular}{lccccc}
\hline Data & \multicolumn{2}{c}{ Power law } & & \multicolumn{2}{c}{ Exponential } \\
\cline { 2 - 3 } \cline { 5 - 6 } & Least squares fit & $\mathbf{R}^{\mathbf{2}}$ & & Least squares fit & $\mathbf{R}^{\mathbf{2}}$ \\
\hline All & $27.3 \mathrm{x}^{-1.6}$ & 0.62 & & $6.1 \mathrm{e}^{-0.18 x}$ & 0.58 \\
\hline Quadrant A & $29.7 \mathrm{x}^{-2.0}$ & 0.72 & $5.2 \mathrm{e}^{-0.28 x}$ & 0.81 \\
\hline Quadrant B & $18.5 \mathrm{x}^{-1.4}$ & 0.82 & & $4.0 \mathrm{e}^{-0.14 x}$ & 0.79 \\
\hline Quadrant C & $193.5 \mathrm{x}^{-2.78}$ & 0.72 & & $17.0 \mathrm{e}^{-0.39 x}$ & 0.87 \\
\hline Quadrant D & $42.3 \mathrm{x}^{-1.44}$ & 0.79 & $9.2 \mathrm{e}^{-0.16 x}$ & 0.82 \\
\hline
\end{tabular}

one deposit. Inspection of the syenite-poor Plinian fall deposit during this study shows that it can be separated into several units, characterised by changes in grain size, sorting and colour (Figure 5). To determine controls on deposit thickness, here the syenite-poor Plinian fall deposit is separated into five units (Figure 5). A finegrained pumice fall deposit (unit 1) is overlain by a finegrained grey ash interpreted as of phreatomagmatic origin (unit 2). Unit 3 is a coarse pumice fall deposit with a sharp upper boundary. Unit 4 is a reverse-graded pumice fall deposit, which contains a number of branch structures preserved in phreatomagmatic ash from unit 2 . A finer-grained pumice fall deposit separates unit 4 from a much coarser pumice fall (unit 5). Overlying the syenitepoor Plinian fall deposit are pyroclastic density current beds that vary from 2 to more than 6 in number, the first of which is labelled as unit 6 . Above the pyroclastic density current rich portion of the deposit is the previously aforementioned syenite-rich Plinian fall, which was not measured in this field study. 'Total' thickness refers to thickness of the syenite-poor pumice fall deposit. Field measurements can be found in Additional file 1 . 


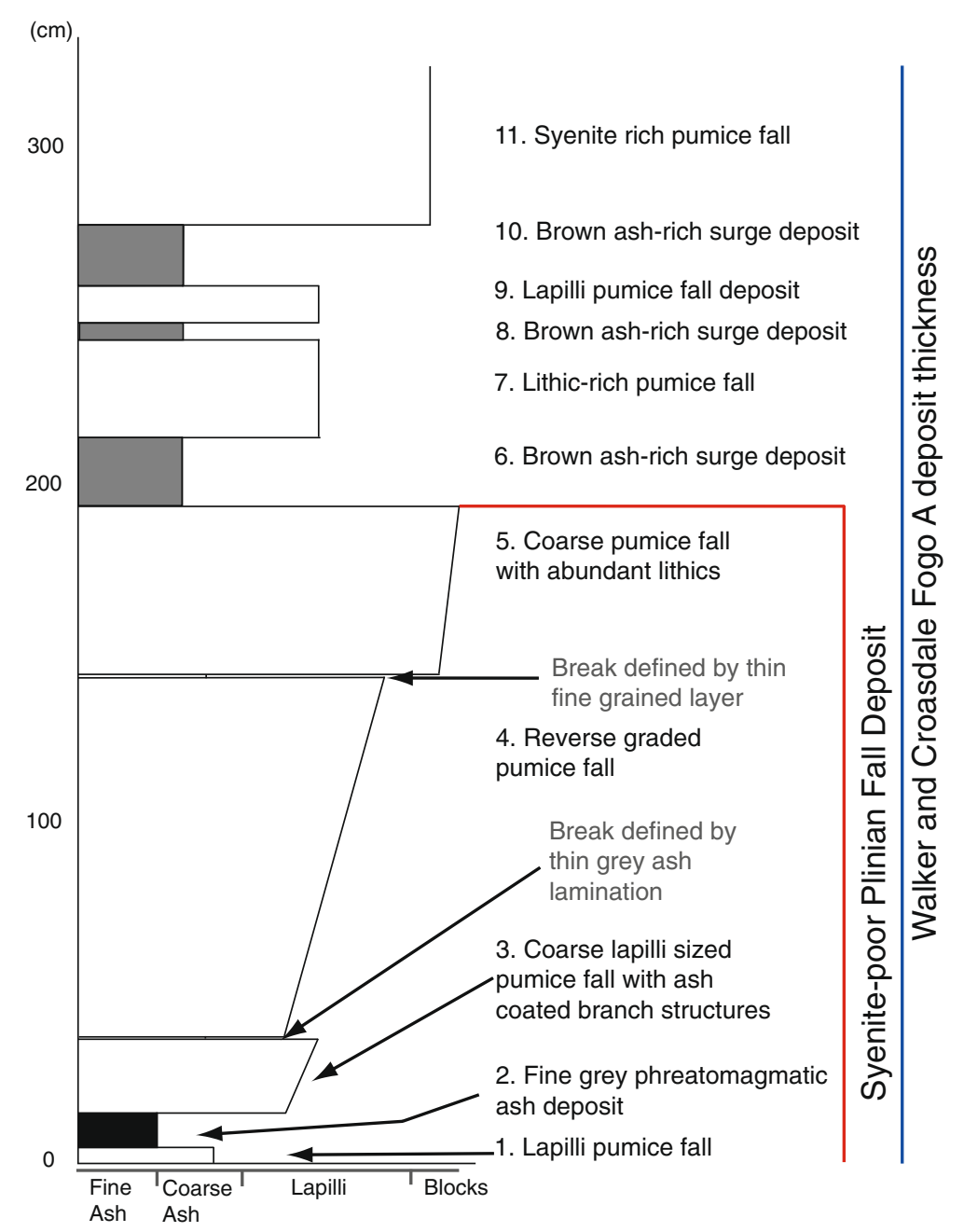

Figure 5 Stratigraphic log of the Fogo A Plinian deposit. Only the syenite-poor Plinian fall (units 1 to 5 ) and the overlying pyroclastic density current deposit (unit 6) thicknesses were measured and the findings analysed in this study.

\section{Natural variability of deposits}

Dirichlet tessellation analysis shows that a single tephra thickness measurement typically represents a deposit area between 0.5 and $10 \mathrm{~km}^{2}$. In addition, K-cluster analysis shows significant variance in deposit thickness within an area of a few $\mathrm{km}^{2}$ unrelated to typical thickness trends related to distance from source. To investigate these trends outcrop scale variance was determined by measuring the thickness of the Fogo A deposit over a number of different spatial scales.

The thicknesses of five fallout units (labelled 1 to 5 in Figure 5), and one pyroclastic density current unit exposed at road cuttings (Loc 2; 629817 E $4176612 \mathrm{~N}$ ), approximately $6 \mathrm{~km}$ from source, were measured at 10 outcrops within a $200 \mathrm{~m}^{2}$ area. The pyroclastic density current was included in the study for comparison with the fall units, despite the different depositional processes. The measurements from an individual scientist were used to calculate percentage error to lessen impacts of different measurement methods or multiple interpretations on uncertainty estimation. Percentage error is calculated as the standard deviation normalised to average thickness for each unit at each of the 10 locations (Figure 6A). There is a clear correlation between stratigraphic position and the natural variability of a deposit with the latter decreasing as fall deposits fill topographic lows, essentially smoothing the local topography. The units at the base of the syenite-poor Plinian fall deposit are the thinnest and are more liable to be affected by undulations in the underlying topography and possible remobilisation before deposition of overlying deposits; they are represented by greater variations (up to $45 \%$ ) than those further up the stratigraphy. These units fill in topographic variations on a scale of 10's $\mathrm{cm}$, producing a more uniformly flat surface on which the later tephra is deposited (variations between 10 and 20\%). The obvious exception to this trend is unit 6 , which shows greater variation (30\%) than would be expected following this 


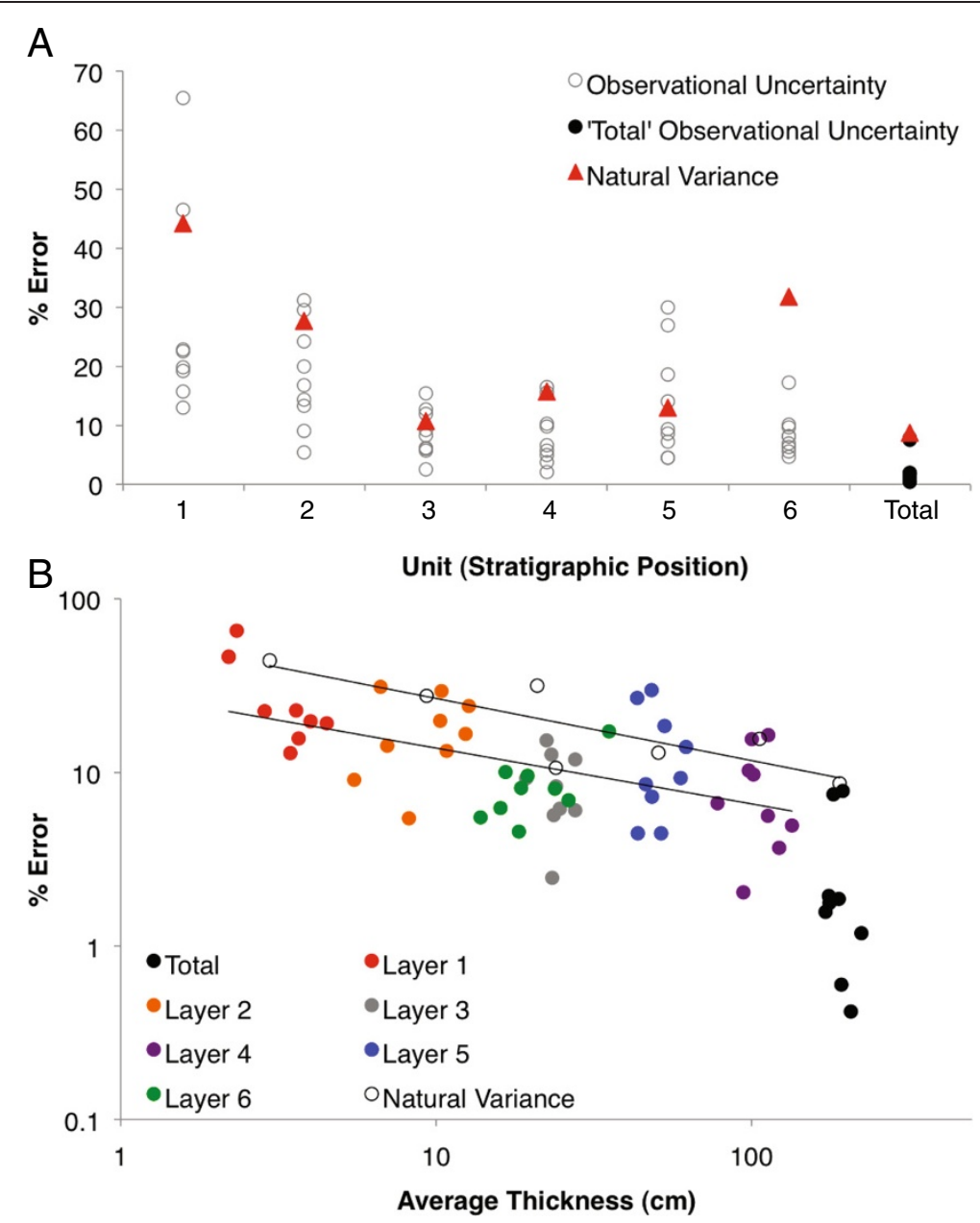

Figure 6 Measurement uncertainties at Loc 2. A. Percentage variation as a function of a unit's position within the deposit. B. Filled symbols represent uncertainties calculated as the percentage difference between measurement standard deviation and the average thickness for each unit at each location. Natural Variance is calculated by averaging measurements for each subunit at Loc 2 and percentage error was calculated as for measurement uncertainties. Regression indicates negative correlations, best described by a power-law relationship for both observational uncertainty $\left(29.0 x^{-0.3} ; R^{2}=0.3\right)$ and natural variance $\left(61.1 x^{-0.4} ; R^{2}=0.7\right)$.

trend. Unit 6 was deposited by a PDC and therefore its thickness is controlled by large-scale topography. The 'total' thickness (which does not include unit 6) shows significantly less variability (9\%) than each component unit. There is also a strong correlation between deposit thickness and variation, with thicker deposits being less variable (Figure 6B).

To further investigate the effect of scale on thickness uncertainty, units 1 to 3 were measured on $0.1,1.0$ and $10 \mathrm{~m}$ spacing along a deposit at a quarry (Loc 5; 632141 E $4175785 \mathrm{~N}$ ), $6 \mathrm{~km}$ south of the source. These measurements were combined with those from Loc 2 that have approximate spacing at $200 \mathrm{~m}$ intervals. At least 10 measurements were taken at each scale. Again measurement standard deviation is normalized to average unit thickness and displayed as percentage error (Figure 7). Unit 1 is highly variable and shows no systematic pattern over different scales. In contrast, units 2 and 3 show thickness variation is greater when measurements are taken every 1 to $10 \mathrm{~m}$ compared to measurements every $0.1 \mathrm{~m}$ and $200 \mathrm{~m}$. These results indicate that uncertainty is largest $(30-45 \%)$ when the scale of topography change is comparable to unit thickness, but decreases significantly when unit thickness is much greater than topography variation scale $(<30 \%)$.

\section{Observational Uncertainties}

Typically in experiments, measurements are repeated several times to provide a spread of values used to assess the uncertainty associated with a single variable. This enables the effects of observational uncertainty related to measurement technique, specifically random errors, to be reduced. During tephra thickness data collection, usually a single measurement is made at a single 


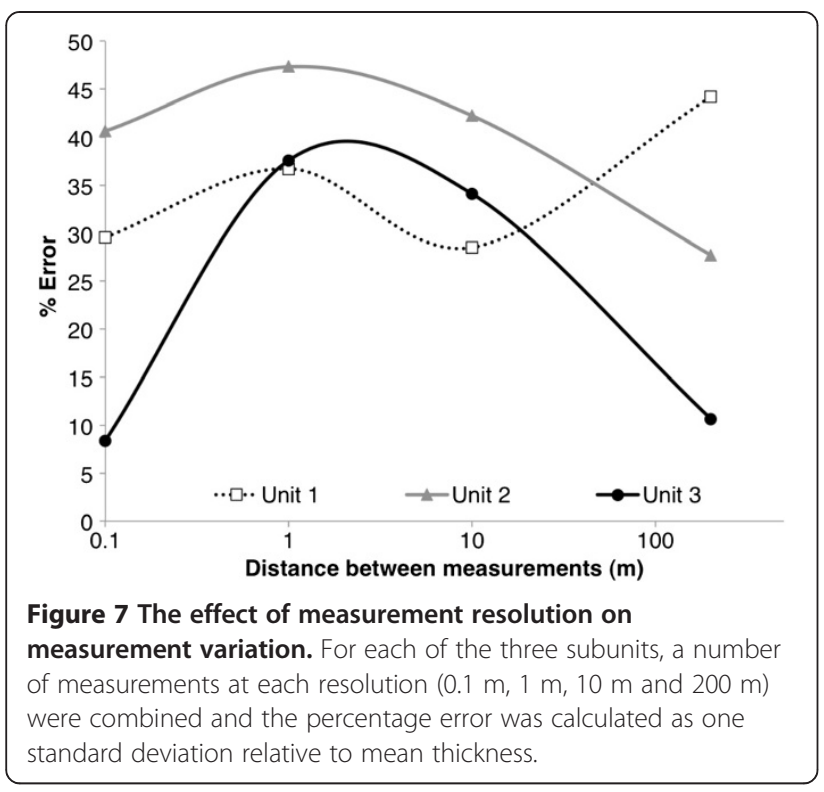

location. As a consequence, such data are liable to include some outliers, with uncertainties associated with inaccuracy and imprecision when measuring a given deposit. For instance, errors can arise from incorrect identification of the limits of the tephra unit or from failure to measure thickness normal to base contact. There is also a tendency to 'fit' measurements (perhaps subconsciously) into convenient user-defined size bins (e.g. to the nearest $10 \mathrm{~cm}$ ), unrelated to the true precision of measurement (Hincks et al. 2013) which, when a large amount of data is collected across a whole deposit, can contribute to an overstating of total volume. In addition, a presumptive mental model may be employed, for example that proximal deposits are thicker than distal deposits. On local scales this assumption can be false, perhaps leading to small-scale variations being unintentionally smoothed out, in the dataset.

To assess the contribution of these measurement biases to thickness and therefore volume estimation, an experiment was conducted to quantify measurement uncertainties. Five scientists measured units 1 to 6 (Figure 5) using a tape measure with a resolution of $1 \mathrm{~mm}$ at Loc. 2 (Figure 1). The measurements (5 for each unit) were pooled to produce a dataset for each unit at each location. Observational uncertainty is calculated as one standard deviation normalized to average thickness expressed as a percentage (Figure 6A). For each of the units there is a large spread in the measurement error (up to 65\%). Unit 6 and the 'total' thickness are exceptions, with much less scatter in the data and comparatively low error $(<18 \%$ and $<8 \%$ respectively). There is a strong correlation between the observational uncertainty and average unit thickness (Figure 6B): thinner units have greater error and therefore larger relative uncertainty than thicker units.
Trends in observational uncertainty closely follow those of natural variance. Again the greatest exception is unit 6 which had low observational uncertainty (Figure 5) but high error associated with natural variance. This is due to the characteristics of this particular deposit. The bounds of unit 6 are well defined and the unit is darker and finer grained than surrounding units. The same is true for the syenite-poor Plinian fall deposit measurement, where unit 6 provides a definite upper bound and the base is defined clearly by the contact with the underlying palaeosol. These characteristics make measurements easier and less subjective, resulting in lower errors and observational uncertainty. As most tephra deposits have a poorly defined upper limit, due to erosion and soil formation, the error estimates provided here may be regarded as a lower limit.

\section{Implications and Conclusions}

To describe the contribution of the different types of uncertainty to overall measurement uncertainty, the natural log of errors from the statistical tests and fieldwork are presented in histograms (Figure 8). This enables direct comparison of error distributions, average error and error standard deviation (Table 2) for the different methods. Here, cluster and exponential error is calculated as the percentage difference between each measured thickness and (a) the average cluster value, or (b) the value predicted by exponential regression. Natural variance and measurement uncertainties for all units were calculated as for Figure 6 and errors from each unit were collated to form a single dataset. For most cases the results show a lognormal distribution of error, however there are clear differences in range and average error for each method.

The average and standard deviation percentage error for each method are presented in Table 2. As described in Figure 4, average error decreases with an increase in number of clusters although the standard deviation varies little. The average error associated with natural variance on scales less than about $200 \mathrm{~m}^{2}$ (28\%) is similar to those associated with the difference between the measurements of Walker and Croasdale (1971) and regression fit to data split into quadrants (19-37\%), and also the error calculated using 20 clusters $(28 \%)$. Natural variability in real world dispersion processes is therefore inferred to explain the within-cluster scatter of data and the disparity between data and regression fit.

Because measurement of such natural variance includes associated observational uncertainty, we propose a typical value of $\sim 30 \%$ as appropriate to describe total measurement uncertainty. The uncertainty associated with observational measurement was quantified separately and has an average of about one-third of the total uncertainty (i.e. 9\%.) The interplay between 

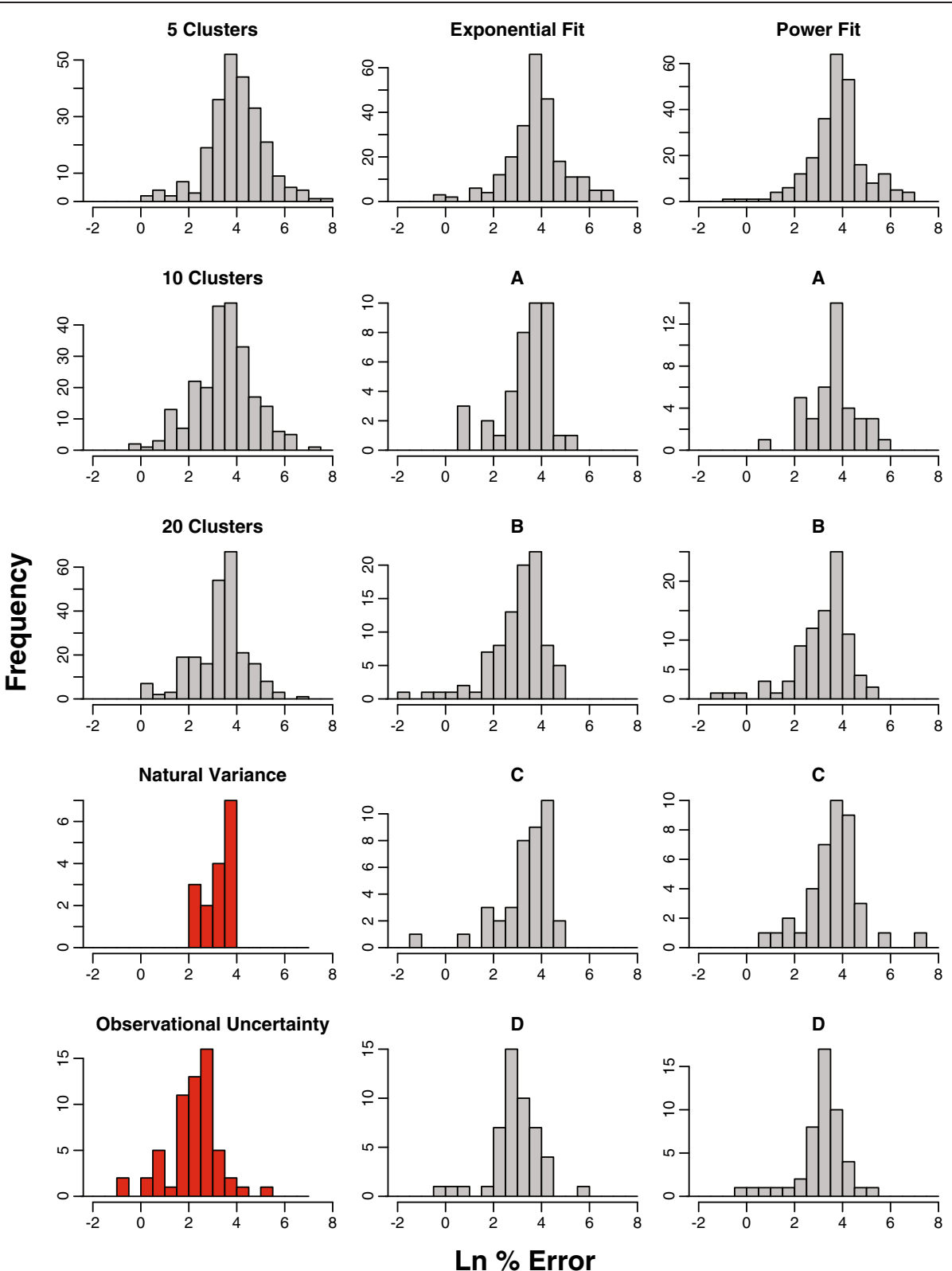

Figure 8 Histograms of natural log of percentage error of thickness measurements determined using cluster analysis (top left), as deviation from expected thickness decay (middle and right hand panels) as a function of distance from source and using field measurements (shown in red). Cluster and exponential error is calculated as the percentage difference between measured thickness and either the average cluster value, or the value predicted by exponential regression. Natural variance and measurement uncertainties calculated as in Figure 7. For most cases these results correspond to lognormal distributions, however there are clear differences in range and mean error for each dataset.

observational uncertainty and natural deposit variability means it is difficult to simply deduct one from the other to produce an overall uncertainty estimate. However, from a first order estimate using propagation of errors associated with observational uncertainty, the residual error associated with natural variance is approximately $26 \%$, showing the net contribution from observational uncertainty is small.
The quantification of uncertainties associated with tephra thickness measurements allows weighting of measurements and therefore more accurate isopachs and volume estimations. Because different data and differing methods are used to determine deposit volumes, large uncertainties can affect not only a single eruption volume estimate but, when comparing different eruption deposits, can distort estimates of eruptive activity through time. 
Table 2 Tephra thickness errors for the Fogo A deposit calculated using statistical methods and fieldwork

\begin{tabular}{lcc}
\hline Method & Average & Standard deviation \\
\hline 5 Clusters & 53 & 3 \\
\hline 10 Clusters & 33 & 3 \\
\hline 20 Clusters & 28 & 3 \\
\hline Regression Fit & 45 & 3 \\
\hline All (Exponential) & $\mathbf{4 4}$ & $\mathbf{3}$ \\
\hline All (Power Law) & 30 & 3 \\
\hline Quadrant A & $\mathbf{3 7}$ & $\mathbf{3}$ \\
\hline Quadrant B & 20 & 3 \\
\hline Quadrant C & $\mathbf{2 0}$ & $\mathbf{5}$ \\
\hline Quadrant D & 28 & 3 \\
\hline Natural Variance & $\mathbf{3 6}$ & $\mathbf{3}$ \\
\hline Observational uncertainty & 19 & 3 \\
\hline
\end{tabular}

Bold text is used to distinguish values determined using power-law as opposed to exponential regression. See text for details of how these values are calculated.

The contribution of thickness measurement uncertainty on volume estimates is dependent on the number of measurements in a dataset. The effect of thickness measurement uncertainty on volume uncertainty was evaluated using the error of a single measurement to estimate the error of the whole population of measurements and therefore volume. If we have $n$ thickness measurements and the uncertainty on an individual measurement is $x$, the standard deviation in the mean is:

$$
\frac{x}{\sqrt{n}}
$$

Following this simple rule, if the number of measurements is small the associated error in volume estimates associated with a given thickness measurement error are much larger than when a large dataset is used. Figure 9 shows how volume uncertainty varies as a function of number of measurements and values of thickness uncertainty. The fewer measurements and greater thickness uncertainty the greater volume uncertainty. For example, a dataset of 10 measurements with an average $30 \%$ uncertainty relates to a volume uncertainty of about $10 \%$, while a dataset of 30 measurements with the same uncertainty would contribute a volume uncertainty of about 5\% (Figure 9). Where error varies spatially in some systematic way as is the case here a weighted mean error can be calculated.

The estimated on land volume of the Fogo A fall deposit is $1.2 \mathrm{~km}^{3}$ (Walker and Croasdale 1971). An average measurement uncertainty of $30 \%$ yields a volume

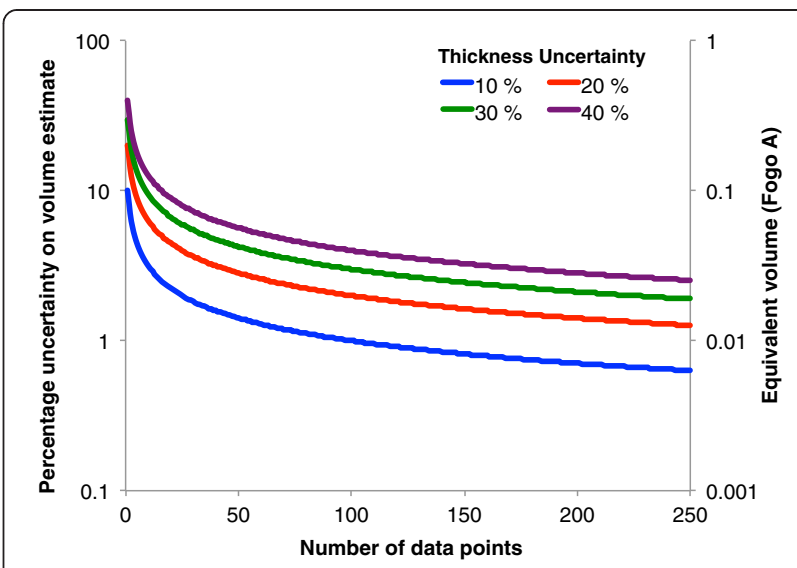

Figure 9 Total deposit volume uncertainty associated with thickness measurement errors and number of data points. Each line corresponds to a different thickness uncertainty. With greater numbers of measurements, uncertainty on the total volume decreases substantially.

uncertainty of $1.3 \%$, equivalent to a volume error $0.02 \mathrm{~km}^{3}$ for the Walker and Croasdale dataset comprised of 250 measurements. Thickness measurement is only one source of volume uncertainty, which will also be influenced by spatial distribution of data, functional forms of fitting isopachs to thickness data, and extrapolation, using these functional forms, of thickness into regions where there is no data. The extent these factors impact on eruption magnitude assessments and other estimates of eruption dynamics, will be discussed further elsewhere.

The uncertainties presented in Table 2 are whole deposit average uncertainties. We have shown that uncertainties vary greatly depending on the underlying topography, the thickness of the deposit and its stratigraphic position, and difficulties in detecting true stratigraphic boundaries. Therefore uncertainties will vary significantly between proximal and distal locations. A further study to compare results from this proximal study with distal deposits would be highly informative. Fine-grained units at the base of the Fogo A deposit provide indicative evidence that these errors are likely to be significant due to direct deposition onto uneven ground and decreased deposit thickness. Remobilization of fall deposits means that over short length scales, thickness variance is high, particularly for thin deposits. In addition, the dark colour and finer grained nature of pyroclastic density current deposits means that deposit boundaries are more easily identifiable.

The findings presented here highlight the need for a standardized method of measuring and reporting tephra thickness in which an estimate of uncertainty is provided for every measurement. Here, we have studied uncertainties in thickness measurements in one particular 
deposit. We therefore recommend that future studies of tephra thickness should endeavour to assess these uncertainties both to better characterize the uncertainty in volume estimates and also to build up a published database of many case studies.

\section{Additional file}

Additional file 1 Table 1. Tephra thickness (cm) at Loc 2 (629817 E $4176612 \mathrm{~N}$ ) with a number of measurements taken within $200 \mathrm{~m}^{2}$. All measurements were conducted by the same person using the same equipment and rationale. Table 2 . Thickness measurements $(\mathrm{cm})$ at Loc $5(632141$ E $4175785 \mathrm{~N})$ with measurements taken every ten metres. Table 3. Thickness measurements $(\mathrm{cm})$ at Loc 5 with measurements taken every 1 metre. Table 4 . Thickness measurements $(\mathrm{cm})$ at Loc 5 with measurements taken every 10 centimeters. Table $\mathbf{5}$. Uncertainty associated with human measurement error. The table shows percentage error calculated for each unit at each location based on pooling measurements from five people. The percentage error is calculated as one sigma of the average value.

\section{Competing interests}

The authors declare that they have no competing interests.

\section{Authors' contributions}

All authors were involved in conceptual design of the study and in drafting and revising the manuscript. SLE and RSJS were involved in acquisition of data. SLE and WPA coordinated design of statistical analysis. SLE carried out analysis and interpretation of the data and drafted the manuscript. All authors have read and approved the manuscript.

\section{Acknowledgments}

This work was supported by an ERC Advanced Research Grant (VOLDIES) to Prof RSJ Sparks FRS. R. Burden and E. Johnston are thanked for their assistance measuring deposits in the field. The manuscript benefited from helpful discussion with R. Blong. Maps were produced using GMT software (Wessel and Smith 1991) and greatly benefitted from the assistance of B. Hemmings. We would like to thank two anonymous reviewers and Chris Newhall who provided detailed suggestions that significantly improved the text.

Received: 6 March 2013 Accepted: 28 June 2013

Published: 10 Sep 2013

\section{References}

Blong R, Enright NJ (2011) Preservation of thin tephras., Unpublished Manuscript http://researchrepository.murdoch.edu.au/5785/1/preservation_of_thin_tephras.pdf Bonadonna C, Costa A (2012) Estimating the volume of tephra deposits: A new simple strategy. Geology 40:415-418

Bonadonna C, Houghton BF (2005) Total grain-size distribution and volume of tephra-fall deposits. Bull Volcanol 67:441-456

Brazier S, Sparks RSJ, Carey SN, Sigurdsson H, Westgate JA (1983) Bimodal grain size distribution and secondary thickening in air-fall ash layers. Nature 30:115-119

Brown RJ, Bonadonna C, Durant AJ (2011) A review of volcanic ash aggregation. Physics and Chemistry of the Earth, Parts A/B/C 45-46:65-78

Burden RE, Chen L, Phillips JC (2013) A Statistical Method for Determining the Volume of Volcanic Fall Deposits. Bull Volcanol 75(6):1-10

Bursik MI, Sparks RSJ, Gilbert JS, Carey SN (1992) Sedimentation of tephra by volcanic plumes: 1. Theory and its comparison with a study of the Fogo A Plinian deposit, Sao Miguel (Azores). Bull Volcanol 54:329-344

Cas RAF, Wright JV (1995) Volcanic Successions: Modern and Ancient. Chapman and Hall, London, 1995

Connor LJ, Connor CB (2006) Inversion is the key to dispersion: understanding eruption dynamics by inverting tephra fallout. In: Mader HM, Coles SG, Connor CB, Connor LJ (eds) Statistics in Volcanology. Special Publications of IAVCEI, 1. Geological Society, London, pp 231-242

Diggle PJ (1983) Statistical Analysis of Spatial Point Patterns. Academic Press, Mathematics in Biology Series
Duffield WA, Bacon A, Roquemore GR (1979) Origin of reverse-graded bedding in air-fall pumice, Coso Range, California. J Volcanol Geotherm Res 5:35-48

Fierstein J, Nathenson M (1992) Another look at the calculation of fallout tephra volumes. Bull Volcanol 54(2):156-167

Guichard F, Carey S, Arthur MA, Sigurdsson H, Arnold M (1993) Tephra from the Minoan eruption of Santorini in sediments of the Black Sea. Nature 363:610-612

Hartigan JA, Wong MA (1979) A k-means clustering algorithm. Applied Statistics 28:100-108

Hincks T, Malamud BD, Sparks RSJ, Wooster MJ, Lynham TJ (2013) Risk assessment and management of wildfire. In: Rougier J, Sparks S, Hill L (eds) Risk and Uncertainty Assessment for Natural Hazards. Cambridge University Press, pp 398-444

Moore RB (1990) Volcanic geology and eruption frequency, Sao Miguel, Azores. Bull Volcanol 52:602-614

Pyle DM (1989) The thickness, volume and grain size of tephra fall deposits. Bull Volcanol 51(1):1-15

Pyle DM (1995) Assessment of the minimum volume of tephra fall deposits. J Volcanol Geotherm Res 69:379-382

Rust AC, Cashman KV (2011) Permeability controls on expansion and size distributions of pyroclasts. J Geophys Res 116:B11202

Sparks RSJ, Bursik MI, Carey SN, Gilbert JS, Glaze LS, Sigurdsson H, Woods AW (1997) Volcanic Plumes. John Wiley and Sons Ltd

Sulpizio R (2005) Three empirical models for the calculation of distal volume of tephra-fall deposits. J Volcanol Geotherm Res 145:315-336

Thorarinsson S (1954) The eruptions of Hekla 1947-1948. The tephra fall from Hekla, Vis Islendinga, Reykjavik 2(3):68

Thorarinsson S, Sigvaldon GE (1972) The Hekla eruption of 1971. Bull Volcanol 36:269-288

Walker GPL, Croasdale R (1971) Two plinian-type eruptions in the Azores. J Geol Soc 127(1):17-55

Walker GPL (1973) Explosive volcanic eruptions-a new classification scheme. Geologische Rund- schau 62(2):431-446

Wessel P, Smith WHF (1991) Free software helps map and display data. Eos 72 (441):445-446

Wright JV, Smith AL, Self S (1980) A working terminology of pyroclastic deposits, J Volcanol Geotherm Res 8:315-336

\subsection{6/2191-5040-2-5}

Cite this article as: Engwell et al:: Quantifying uncertainties in the measurement of tephra fall thickness. Journal of Applied Volcanology $2013,2: 5$

\section{Submit your manuscript to a SpringerOpen ${ }^{\odot}$ journal and benefit from:}

- Convenient online submission

- Rigorous peer review

- Immediate publication on acceptance

- Open access: articles freely available online

- High visibility within the field

- Retaining the copyright to your article

Submit your next manuscript at $>$ springeropen.com 